\title{
Headache Medicine
}

\section{A incapacidade cervical está relacionada à frequência de crises de migrânea e à presença de aura}

\author{
Gabriella Tolentino, Carina Pinheiro, Lidiane Florencio, Anamaria de Oliveira, Cesar Fernandez-de-Las-Peñas, Fabíola \\ Dach, Debora Bevilaqua-Grossi \\ Universidade de São Paulo
}

\section{Introdução}

A presença de dor cervical é bem conhecida no quadro de migrânea, bem como a associação entre e a alta frequência de crises e maior incapacidade cervical. No entanto, pacientes com aura apresentam alguns fatores que não são observados em indivíduos sem aura, e a incapacidade cervical ainda não foi investigada neste grupo de pacientes. O objetivo do estudo foi comparar os níveis de severidade da incapacidade relacionada à dor cervical entre pacientes com migrânea com e sem aura e migrânea crônica.

\section{Métodos}

Sessenta e duas mulheres com migrânea foram avaliadas e divididas em 3 grupos: Migrânea episódica sem aura (MoA, n=18, idade 32,3; DP 9,3), migrânea episódica com aura (MA, n=17, idade 32,8; DP 8,8) e migrânea crônica (CM, n=26, idade 34,1; DP 9,8). O diagnóstico foi fornecido por um neurologista de acordo com a terceira edição da Classificação Internacional das Cefaleias. Todos os participantes completaram o questionário Neck Disability Index e a severidade da incapacidade foi registrada. Os grupos foram comparados pela severidade da incapacidade usando o teste quiquadrado $(p<0,05)$. O estudo foi aprovado pelo Comitê de Ética em Pesquisa do Hospital das Clínicas de Ribeirão Preto-SP (n¹2145/2016).

\section{Resultados}

Não foram observadas diferenças na idade, tempo de migrânea e intensidade da migrânea $(p>0,05)$. A distribuição da severidade da incapacidade cervical foi diferente entre os grupos $(x 2=21,89, p=0,001)$. Os grupos MA e MC apresentaram menor proporção de indivíduos sem incapacidade ( $0 \%$ e 7,7\%, respectivamente) do que o grupo MoA. Nos grupos MA e CM também foi observada maior frequência de indivíduos com incapacidade moderada do que o grupo MoA (MA 52,9\%, MC 38,5\%, MoA 5,6\%).

\section{Conclusão}

A incapacidade relacionada à dor cervical é altamente prevalente em indivíduos com migrânea. No entanto, nos pacientes com aura e migrânea crônica, essa incapacidade apresenta- níveis mais severos.

Palavras-chave: cefaleia, dor cervical, incapacidade.

Estudo financiado pela FAPESP - processo 2015/18031-5. 